\title{
State of the Relationship between Bronchial Asthma and Psychological Factors
}

\author{
Juan Carlos Fernández Rodríguez*
}

\author{
Department of Psychology, Universidad Antonio de Nebrija, Calle Santa Cruz de Marcenado, Madrid, Spain
}

${ }^{*}$ Corresponding author: Juan Carlos Fernández Rodríguez, Director, Department of Psychology, Universidad Antonio de Nebrija, Calle Santa Cruz de Marcenado 27 Madrid, Spain, Tel: 34914521103; E-mail: jfernanr@nebrija.es

Received: November 29, 2017; Accepted: December 01, 2017; Published: December 07, 2017

Citation: Rodríguez JCF (2017) State of the Relationship between Bronchial Asthma and Psychological Factors. Ann Clin Lab Res Vol.5: No.4: 204.

\section{Editorial}

Asthma is, without a doubt, a typical disease of mankind. In fact, it was already described by Hippocrates in the 4th Century before Christ. Despite how long it has been, specialists have not been able to agree on the definition of the disease and its main characteristics. The reasons for this are that bronchial asthma symptoms can occur in other diseases and its etiopathogenesis has not been completely clarified yet, which makes it very difficult to classify. Even the diagnostic criteria are of different nature and not unanimously shared.

We can define asthma as a reversible and obstructive lung disorder, defined by a hyper-responsiveness of the respiratory tract to a range of stimuli. More specifically, Cisneros, López, Ramírez and Almonacid define asthma as a disease originated by the presence of a chronic inflammation of the respiratory tract, associated to bronchial hyper-responsiveness, and its course typically includes reversible bronchial obstruction episodes, with or without treatment [1].

Bronchial asthma can be a very important problem in the life of the patient who suffers from this disease, in many occasions it can cause serious restrictions in the lifestyle of the person. This situation is especially important in the child population, since the conditions can reach deficiencies both at the academic level and social level, with the serious consequences that the deficiencies can come to mean in childhood and the future development of the future patient [2]. In addition, bronchial asthma is a major public health problem due to its economic price [3].

At present there is a large amount of data that explain or at least nuance the relationship that psychological factors have with physical illness and health in general. Emotions are the psychological factors that can have the greatest influence on physical illness, in fact, more and more studies show how emotional factors are linked to digestive, vascular, respiratory disorders and those related to a failure of the immune system, like cancer or to a large extent bronchial asthma. There is evidence to affirm that psychosocial factors play an important role in the variability of physical illness, evolution, morbidity and treatment [4]. Despite advances in treatment, poor control of the disease is observed. Martínez-Moragon points out a factor associated with poor control of the disease: the existence of a stressful event in a recent way, always based on the patient's own opinion [5]. When this stressful event occurs, the probability that the disease is poorly controlled is more than doubled.

Psychological treatments in bronchial asthma have abundant empirical evidence on two important ways of influencing emotional and behavioral factors in bronchial asthma: the direct influence of lung function and the influence on morbidity parameters Self-management programs are fundamental for the treatment of asthma. Active participation of patients is essential in the programs [6].

The psychological variables related to bronchial asthma cannot be considered in isolation, especially in the case of patients of infantile age. Psychological factors often act according to a circular model, affecting the patient's problems to the family and family problems to the patient, demonstrating a relationship between family processes and asthmatic symptoms.

It is necessary to identify not only the factors that affect the quality of life of the patient, but the family, only in this way can asthma be treated, within a comprehensive approach of the disease [7].

Up to this date, the direction of the relationship between asthma, emotion and other psychological factors is not proved. In patients with asthma, it is necessary to consider that psychological variables play an important role, so in the face of treatment, it will be necessary to implement psychological intervention strategies, not only in adult patients, but also to include children and adolescents. Neither do we possess a complete knowledge of the patient's personal variables, it seems clear that the presence of negative emotions, inappropriate expectations, the stigmatization that the disease can produce or the deficient coping styles correlate positively with the severity of asthma and the poor control exercised by the patient of his illness. These factors imply worse evolution and worse prognosis of the disease [8]. Future research should include longitudinal cohorts and multidisciplinary teams [9].

In summary, not only asthma should be considered as a strict biological problem and only approachable from a medical perspective. The psychological factors are intimately related to the disease and to the asthmatic patient. A complete approach to asthma must be carried out considering the psychological, family and social aspects of the asthmatic. Psychological factors, play can play an important role in the 
pathogenesis and physiopathology of asthma, either through physiological mechanisms or indirectly through different factors of lifestyle, cognitions, health habits, management of the disease, etc.

\section{References}

1. López CC, Ramírez MT, Almonacid C (2009) Asthma. In: Miguel J, Álvarez Sala R (eds). Manual of Clinical Pulmonology. Ergon. Madrid, Spain.

2. Fernández-Rodríguez JC, Miralles F (2015) Presence of depression in patients with asthma and its influence on their families. Yearbook of Psychology 45: 361-374.

3. Melero C, Rodríguez N, Díaz R (2017) Adherence to treatment in asthma. Current situation. Asthma Magazine 2: 13-22.

4. Yousef E (2014) Psycho social stresses and asthma morbidity in children. J Allergy Clin Immunol 133: 79.
5. Martínez Moragón E (2010) Asthma control: A distant goal. Archivos de Bronconeumología, 46: 347-348.

6. Vázquez MI, Romero-Frias E, Sández E (2011) Guide to effective psychological treatments in bronchial asthma. Pérez Álvarez $\mathrm{M}$, Fernández Hermida JR, Fernández C, Amigo I (eds). Guide to effective psychological treatments II. Madrid: Pyramid. pp. 23-55.

7. Fasciglione MP, Castañeiras CE (2010) The educational component in the comprehensive approach to bronchial asthma. J Bras Pneumol 36: 252-259.

8. Cano-Vindel A, Fernández-Rodriguez JC, Spielberger C (2012) The experience and expression of anger and anxiety in bronchial asthma patients. Anxiety and Stress 18: 221-230.

9. Levy BD, Noel PPJ, Freemer MM, Cloutier MM, Georas SN, et al. (2015) Future research directions in asthma. An NHLBI Working Group Report. Am J Respir Crit Care Med 192: 1366-1372. 